\title{
Socialt kapital och hälsa - en forskningsöversikt
}

\author{
FREDRICA NYQVIST
}

\begin{abstract}
Tyngdpunkten $i$ denna artikel ligger på mätningen av socialt kapital och på aktuella frågor $i$ samband med socialt kapital och hälsostudier. Forskningen om socialt kapital och hälsa har kritiserats och i artikeln diskuteras den kritik som riktats mot att forskningen inte bidrar med nya insikter till hälsovetenskapen. Det finns två infallsvinklar $i$ texten: dels utgås från ett individperspektiv där betydelsen av individens sociala nätverk lyfts fram, dels diskuteras hur begreppet socialt kapital har teoretiserats och operationaliserats på en övergripande nivå.
\end{abstract}

Det finns idag ett stort vetenskapligt intresse för begreppet socialt kapital. I forskningslitteraturen läser vi att socialt kapital har en positiv inverkan på demokratin, välbefinnandet, den fysiska och mentala hälsan, livskvaliteten, brottsligheten och den ekonomiska tillväxten (Putnam 1996, Kawachi et al. 1997, Hyyppä \& Mäki 2001a, 2001b, McCulloch 2001, Putnam 2000, Sampson \& Roudenbush 1997, Knack \& Kneefer 1997). På grund av det stora

Fredrica Nyqvist är doktorand vid den samhällsvetenskapliga institutionen, Åbo Akademi intresset för socialt kapital finns det en risk för att det blir ett överexploaterat begrepp med oklarheter när det gäller definitionen, mätningen och effekterna. Begreppet socialt kapital har kritiserats för att tills vidare vara för empiriskt outvecklat för att kunna bidra med nya insikter till hälsoforskningen (Hawe \& Shiell 2000). För att förstå en del av kritiken som riktats såväl internt mot forskningen om socialt kapital, dess operationalisering och genomförande som mot förklaringsvärdet av socialt kapital i jämförelse med relaterade begrepp, beskriver jag kort de teoretiska huvudinriktningarna 
för att fånga oklarheterna beträffande det sociala kapitalets innehåll. Därefter övergår jag till att beskriva nyckelbegreppen och hur dessa har använts inom forskningen kring socialt kapital. Jag sammanfattar studier som mäter socialt kapital och hälsa och avslutar med relevanta frågor i samband med dessa mätningar.

\section{De främsta teoretikerna inom socialt kapital}

James Coleman (1926 - 1995) använde flera empiriska exempel från skolvärlden för att förklara skillnaderna mellan olika former av kapital och deras betydelse för främjandet av barnens skolgång. Han urskiljer tre former av kapital inom familjen: ekonomiskt och socialt kapital samt humankapital (Coleman 1988). Även om ekonomiskt kapital och humankapital är nödvändiga för att utbilda barnen så behövs socialt kapital inom familjen, dvs. en relation mellan föräldrar och barn där föräldrarnas roll i inlärningssituationen påverkar barnens skolgång. Därtill lyfter Coleman fram socialt kapital utanför familjen, vilket innefattar relationen mellan skolan och föräldrarna. Ett slutet nätverk mellan skolbarnen och föräldrarna ökar nivån av socialt kapital hos de enskilda föräldrarna, vilket har en positiv inverkan på barnens uppfostran. Coleman anser vidare att ett unikt karaktärsdrag hos socialt kapital är att det existerar i relationer mellan individer och att effekten inte är exklusiv för individen utan påverkar alla som finns inom en relevant struktur såsom familjen. Liksom när det gäller andra offentliga varor finns det en risk för att individerna inte investerar optimalt i socialt kapital. Orsaken är främst osäkerheten i att investera i sociala relationer då man inte kan kontrollera andra individers beslut och val. Om en individ försvinner från nätverket påverkar detta alla i nätverket och investeringen $\mathrm{i}$ just den individen kan ha varit bortkastad. Eftersom socialt kapital ofta är en biprodukt av andra aktiviteter kompenseras ändå underinvesteringen vanligtvis (Coleman 1990).

Svagheterna i Colemans teori har diskuterats av Alejandro Portes (1998 s. 5). Portes kritiserar Colemans definition och anser den vara oprecis vilket leder till att redan kända processer får en ny "etikett» och hamnar i kategorin socialt kapital. Den oklara indelningen leder dessutom till tautologiska påståenden, som härstammar från att man inte drar en klar linje mellan individens nätverk och de fördelar individen uppnår genom nätverket. Portes kritiserar även Coleman för att han påstår att det mest effektiva nätverket är slutet och tätt medan andra teoretiker som Mark Granovetter (1973) och Ronald Burt (1992) påstår det motsatta. Granovetter (1973) använder inte själv begreppet socialt kapital, men hans arbete om de svaga bandens styrka (the strength of the weak ties) har influerat Burts (1992) resonemang om de strukturella tomrummens (structural holes) betydelse för socialt kapital. Det är med andra ord positionen i nätverket och nätverksmönstret som är betydelsefullt i analysen, men vilket som är det mest effektiva nätverket råder det olika uppfattningar om. I figur 1 illustreras två olika nätverksstrukturer enligt Burt och Coleman. I nätverket till vänster är mittenpositionen den 
mest effektiva i t.ex. konkurrenssituationer om jobb medan det slutna nätverket till höger är det mest effektiva vid exempelvis barnuppfostran.

\section{Figur I.}

Socialt kapital $i$ två olika nätverksstrukturer.

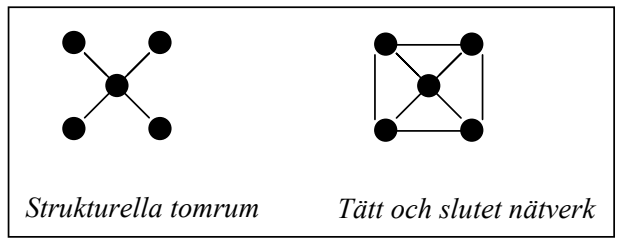

Kärnan i denna nätverksinriktning utgörs av två hypoteser: 1) resurshypotesen, ju mera socialt kapital individen har desto bättre kommer han att uppnå sina mål och 2) investeringshypotesen, individen investerar i en relation beroende på det förväntade värdet på framtida fördelar (Flap 1999). Förutom Coleman finns bl.a. teoretikerna Nan Lin (1999), Ronald Burt (1992) och Henk Flap (1999) representerade i nätverkskategorin.

Intresset för begreppet socialt kapital ökade emellertid då diskussionen inleddes om att socialt kapital är en resurs för ett större kollektiv och inte enbart för den enskilda individen. Robert D. Putnam är den främsta företrädaren för detta synsätt i och med publiceringen av Den fungerande demokratin (Putnam 1996).

I den "putnamska» inriktningen ligger fokuseringen på en samfundsnivå och den kollektiva nyttan av socialt kapital (se Lin 1999). Inom detta synsätt fokuserar man på sociala nätverk, ömsesidighetsnormer och tillit och på hur dessa attribut inverkar på samfund, regioner och stater. Resultatet av Putnams studie i Italien (Putnam 1996) visade att socialt kapital kunde vara en förklarande faktor till att regioner utvecklas olika gällande demokrati, ekonomi och välbefinnande. Putnams slutsats var att civilt engagemang och social sammanhållning är viktiga för den demokratiska utvecklingen. Enligt Putnam består socialt kapital av jämlikhet, sociala nätverk, civilt engagemang, tillit mellan medborgare och reciprocitetsnormer. Dessa attribut förbättrar samhällets effektivitet och utvecklar demokratin i och med att de underlättar samordnade aktioner.

Den kritik som riktats mot Putnams forskning om socialt kapital gäller främst cirkelargumentationen, dvs. att socialt kapital är både ursprunget till och effekten av olika positiva attribut (Woolcock 1998, 2001, Portes 1998). På grund av oklarheterna beträffande ursprunget och effekterna har exempelvis steget mellan teori och empirisk metod blivit för stort (Stone 2001). En annan osäkerhetsfaktor är kausaliteten. Även om det finns indikationer för åt i vilken riktning "pilarna" visar kan man idag inte med säkerhet fastställa vad som påverkar vad.

\section{Socialt kapital - sociala nätverk, reciprocitet och tillit}

Trots olika teoretiska inriktningar är många forskare överens om att huvudkomponenterna i socialt kapital är socialt nätverk, reciprocitet och tillit. Beträffande socialt nätverk finns det inte några gemensamma riktlinjer för operationalisering eller för mätmetoder. En av orsakerna till detta är den oklara definitionen av begreppet socialt 
nätverk. Som ett exempel på detta används begreppen socialt stöd och socialt nätverk ofta synonymt trots att definitionerna skiljer sig åt. Socialt stöd kan definieras som instrumentella och emotionella resurser som andra står till tjänst med (Cohen \& Syme 1985) medan ett socialt nätverk däremot består av en uppsättning av förbindelser mellan identifierbara grupper av människor (Mitchell 1969).

Under de senaste 30 åren har mätningen av sociala nätverk utvecklats från användningen av enkla indikatorer såsom civilstånd, kontakter med vänner och medlemskap i frivilliga organisationer till studier där man mäter såväl strukturen som karaktären hos nätverket. Utvecklingen inom nätverksstudierna är slående då man studerar de dimensioner som presenteras av Lisa F. Berkman m.fl. (2000) där man skiljer strukturen i nätverket från dess karaktärsdrag. I strukturen ingår variabler såsom storlek, täthet och styrka medan karaktärsdragen mäter kontaktfrekvensen, ömsesidigheten och stödet. En lite annorlunda indelning presenteras av Ann Bowling (1991, s. 121). Bowling identifierar dimensionerna storlek, geografisk spridning, täthet/integration, uppbyggnad och enhetlighet, kontaktfrekvens och styrkan av relationen.

Inom forskningen om socialt kapital utgör sociala nätverk en av nyckelkomponenterna och exempelvis Putnam (2000) åtskiljer informella och formella nätverk. I informella nätverk ingår relationer till familjemedlemmar, släktingar, vänner och grannar medan formella nätverk finns inom frivilliga organisationer och andra föreningar. Putnam skiljer dessutom på överbyggande nätverk (bridging) och sammanbindande nätverk (bonding). De två nätverken fyller olika funktioner. Sammanbindande nätverk finns inom det egna nätverket och är bra för att stärka solidariteten och sammanhållningen inom gruppen, medan överbyggande nätverk är bra för exempelvis informationsspridning och för att få tillgång till stöd utanför det egna nätverket.

En kritik som riktats mot sättet att mäta nätverken inom socialt kapital är att kvaliteten i nätverket vanligtvis inte uttryckligen mäts. Exempelvis är medlemskap i organisationer en vanlig fråga i forskningen om socialt kapital, men ifall den här informationen inte kombineras med information om kvaliteten på relationen får vi egentligen bara upplysningar om hur individen spenderar sin fritid (Stone 2001). Bland annat Lin (1999) önskar att forskningen om socialt kapital i högre grad skulle använda den kunskap som finns bland nätverksteoretiker där liknande metodologiska frågor har diskuterats.

Wendy Stone (2001) anser att socialt kapital inte enbart kan mätas genom nätverksstudier utan att nätverksinformationen måste kombineras med normmätningar, det vill säga mätningen av ömsesidigheten i nätverket och tilliten.

\section{Figur 2.}

Dimensioner i socialt kapital.

\begin{tabular}{|ll|}
\hline & \multicolumn{2}{l|}{$\begin{array}{l}\text { Kvalitet } \\
\text { Struktur } \\
\text { socialt nätverk } \\
\text { ömsesidighet }\end{array}$} \\
Ref.: Stone 2001 & \\
\hline
\end{tabular}


Det finns ett nära förhållande mellan tillit och ömsesidighet. Coleman (1988 s. 102) beskriver förhållandet mellan tillit och ömsesidighet på följande sätt:

If $A$ does something for $B$ and trusts $B$ to reciprocate in the future, this establishes an expectation in $A$ and an obligation on the part of $B$. This obligation can be conceived as a credit slip held by $A$ for performance by $B$.

Reciprocitet är således när individen medverkar till andra människors välfärd med förväntningen att gärningen återgäldas i framtiden. Socialt kapital är i hög grad beroende på tilliten om att gärningarna förväntas återgäldas, och ifall tilliten missbrukas har reciprociteten mist sin betydelse som en form av kapital. Några exempel på hur reciprocitet har operationaliserats finner man i Jenny Onyx och Paul Bullens (1997) undersökning utförd i Australien där man har låtit respondenten ta ställning till påståendet som "genom att hjälpa andra hjälper man sig själv i det långa loppet« eller genom att besvara frågan: "under de senaste 6 månaderna, har du gjort en tjänst åt en sjuk granne».

Det pågår en debatt om huruvida tillit är en del av definitionen, en effekt av socialt kapital eller uppkomsten till kapitalet. Putnam använde tillit som en del av definitionen av socialt kapital i Den fungerande demokratin (1996) men har senare ifrågasatt detta (2000, 2001). Michael Woolcock (2001) hävdar att tillit är en effekt av socialt kapital eftersom individerna investerar i nätverk och sociala institutioner som producerar tillit medan Frances Fukuyama (1999) anser att tillit är en viktig biprodukt av socialt kapital. Trots detta använder de flesta författarna tillit som en del av begreppet. En vanlig tillitsfråga som används i bl.a. The World Value Survey (1995-1997) lyder:

Tycker Du att man allmänt sett kan lita på de flesta människor, eller att man inte kan vara nog försiktig $i$ kontakten med andra människor?

Det har höjts flera kritiska röster mot att använda enbart denna fråga som ett mått på tillit främst på grund av att tillit är ett mångdimensionellt begrepp (t.ex. Stone 2001). En utgångspunkt är att indela tillit i 1) förtroende för olika organisationer och institutioner såsom polisen, riksdagen och domstolsväsendet, 2) tillit till vänner och familj och 3) tillit till okända personer. Idén om att åtskilja tillit till personer och förtroende för institutioner och organisationer härstammar från teoretiker som exempelvis Luhmann (1979) och Seligman (1997).

\section{Socialt kapital och hälsa}

\section{Individnivå}

Det finns en rätt lång tradition att mäta socialt nätverk och dess samband med god hälsa. En av de första epidemiologiska studierna som mätte socialt nätverk och hälsa är den kända Alameda County-studien (Berkman \& Syme 1979). I denna studie användes enkla indikatorer för att mäta sociala nätverk och deras påverkan på mortaliteten. Efter Alameda Countystudien bekräftades sambandet mellan socialt nätverk och hälsa i en mängd olika studier, dock med reservationen att sociala

Fredrica Nyqvist: Socialt kapital och hälsa - en forskningsöversikt. 
nätverksstudier inte följer en enhetlig linje utan innehåller olika element såsom sociala aktiviteter, sociala relationer, socialt stöd och sociala nätverk. I tabell 1 ges exempel på några studier som mäter socialt nätverk, stöd och hälsa.
Det finns starka samband mellan social integrering och lägre dödlighetsrisk samt mental hälsa. Studier som mäter sambandet mellan social integrering och fysiska hälsa uppvisar inte lika övertygande resultat (se t.ex. Seeman 1996).

\section{Tabell I.}

Ett exempel av studier som mäter socialt nätverk, stöd och hälsa.

\begin{tabular}{|c|c|c|c|}
\hline Studier & $\begin{array}{l}\text { Undersöknings- } \\
\text { grupp och uppfölj- } \\
\text { ningsstudie }\end{array}$ & Operationalisering & Resultat \\
\hline $\begin{array}{l}\text { Avlund m.fl. } \\
1998 \\
\text { Danmark }\end{array}$ & $\begin{array}{l}\text { 734 70-åringar } \\
\text { | I år }\end{array}$ & $\begin{array}{l}\text { Sociala relationer; } \\
\text { bo ensam, ha barn, } \\
\text { kontakt med barn, } \\
\text { barnbarn, vänner, släk- } \\
\text { tingar, stöd, aktiviteter, } \\
\text { hjälpa andra. }\end{array}$ & $\begin{array}{l}\text { Ett samband mellan sociala } \\
\text { relationer och dödlighet, } \\
\text { men två aspekter av } \\
\text { sociala relationer har mer } \\
\text { betydelse; att få stöd och } \\
\text { att hjälpa andra med olika } \\
\text { uppgifter. Sociala relationer } \\
\text { kan ha olika funktioner för } \\
\text { män och kvinnor. }\end{array}$ \\
\hline $\begin{array}{l}\text { Berkman \& } \\
\text { Syme } 1979 \\
\text { USA }\end{array}$ & $\begin{array}{l}4174 \text { vuxna } \\
17 \text { år }\end{array}$ & $\begin{array}{l}\text { Civilstånd, kontakter } \\
\text { med släktingar och } \\
\text { vänner, medlemskap i } \\
\text { kyrka/andra grupper. }\end{array}$ & $\begin{array}{l}\text { Ett samband mellan sociala } \\
\text { band, integrering i samhället } \\
\text { och dödlighet. }\end{array}$ \\
\hline $\begin{array}{l}\text { Fratiglioni m.fl. } \\
2000 \\
\text { Sverige }\end{array}$ & $\begin{array}{l}1203(75+) \\
3 a ̊ r\end{array}$ & $\begin{array}{l}\text { Sociala nätverk: } \\
\text { civilstånd, boendear- } \\
\text { rangemang, ha barn, } \\
\text { kontaktfrekvens, } \\
\text { tillfredsställelse med } \\
\text { kontakter, sociala band } \\
\text { med släktingar och } \\
\text { vänner. }\end{array}$ & $\begin{array}{l}\text { Individer som bor } \\
\text { ensamma och de utan } \\
\text { några nära sociala kontak- } \\
\text { ter hade en relativt högre } \\
\text { risk för att utveckla demens } \\
\text { vid en jämförelse med gifta } \\
\text { som bor tillsammans med } \\
\text { någon annan. }\end{array}$ \\
\hline $\begin{array}{l}\text { Jylhä \& Aro } \\
\text { 1989 } \\
\text { Finland }\end{array}$ & $\begin{array}{l}1060 \text { i åldern 60-80 år } \\
6.5 \text { år }\end{array}$ & $\begin{array}{l}\text { Civilstånd, bo ensam, } \\
\text { närhet till barn, index } \\
\text { av sociala kontakter } \\
\text { och index av socialt } \\
\text { deltagande. }\end{array}$ & $\begin{array}{l}\text { Sociala nätverk hade inte } \\
\text { något samband med } \\
\text { överlevnad. Men då socialt } \\
\text { deltagande analyserades } \\
\text { som en kontinuerlig varia- } \\
\text { bel fann man ett samband } \\
\text { med dödlighet. }\end{array}$ \\
\hline
\end{tabular}


Det finns olika förklaringar om mekanismerna mellan sociala nätverk och hälsa. En förklaring utgår från att nätverket påverkar individens hälsobeteenden såsom motionsvanor, alkohol- och tobaksvanor. En annan förklaring utgår från psykologiska mekanismer, dvs. ett socialt nätverk kan stärka självkänslan, det stöder vid stressituationer och kan ge en känsla av välbefinnande. Det finns även en fysiologisk förklaringsmekanism. Man har bland annat konstaterat att blodtrycket sjunker vid social integrering och att immunsystemet förstärks (Berkman \& Glass 2000).

Trots att de flesta studierna tar i beaktande det positiva förhållandet mellan social integrering och hälsa får man inte glömma att sociala relationer även kan leda till negativa upplevelser som konflikter, avundsjuka och besvikelser (Thoits 1985). Studier visar att ett socialt nätverk inom vissa grupper nästan kan likställas med ett risknätverk för individen när det gäller spridning av sjukdomar såsom HIV (Neaigus et al. 1994).

\section{Kollektiv nivå}

Intresset för forskningen kring socialt kapital ökade då det utvidgades som en resurs för en grupp eller samhälle snarare än för den enskilda individen (Putnam 1996). Under det senaste tio åren har en ansenlig mängd forskning publicerats om sambandet mellan socialt kapital och hälsa (se Macinko \& Starfield 2001) utgående från den putnamska traditionen och en översikt av några studier finns i tabell 2 där fokuseringen är på operationalisering och på effekten av socialt kapital.
Som det framgår ur tabell 2 så saknas det en enhetlig linje vilket gör det svårt att jämföra metoderna och resultaten med varandra. Socialt kapital operationaliseras med variabler såsom tillit, deltagande i frivilliga organisationer, integrering i samhället och i grannskapet. Inkluderandet av tillitsvariabler i studierna i tabell 2 är egentligen den enda uppenbara skillnaden jämfört med studierna i tabell 1, där man istället fokuserat på kvalitetsaspekter på relationerna. I Finland (Hyyppä \& Mäki 2001a, 2001b) visade resultatet att socialt kapital kan vara en förklarande faktor till finlandssvenskarnas bättre hälsa, funktionsförmåga och längre livslängd. I Ryssland (Rose 2000) spelade det sociala kapitalet en större roll för hälsan än humankapitalet och i USA (Kawachi et al. 1997) fann man ett samband mellan mortalitet och socialt kapital. I Storbritannien (McCulloch 2001) användes data från British Household Panel Study i analysen och där fann man ett samband mellan litet socialt kapital och psykisk sjuklighet. Skillnaderna i hur socialt kapital har operationaliserats kan delvis förklaras med att ett flertal av studierna är baserade på sekundärdata som inte ursprungligen var utarbetad för att mäta socialt kapital.

Markku T Hyyppäs och Juhani Mäkis (2001a, 2001b) studie i Finland har dock uttryckligen utarbetats för att mäta socialt kapital och hälsa och det är därför intressant att närmare granska deras undersökning. Det empiriska materialet insamlades med hjälp av postenkäter som skickades ut till 1000 svenskspråkiga och lika många finskspråkiga i Finland och den totala svarsprocenten var 62,6 procent. Resultatet visade att hälsoriskfaktorer såsom ålder,

Fredrica Nyqvist: Socialt kapital och hälsa - en forskningsöversikt. 
BMI (Body Mass Index), familjeinkomster och rökning förklarade 14 procent av variationen av den självuppskattade hälsan. Förklaringsvärdet steg till 23 procent då kroniska sjukdomar ingick i modellen och steg med ytterligare ett par procentenheter då brister i funktionsförmågan inkluderades. Socialt kapital variabler såsom hjälpande vänner, misstro mot medmänniskor, deltagande i religiösa aktiviteter, att vara född på annan ort, medlemskap i frivilliga organisationer och deltagande i hembygdsföreningar, samt körsång inkluderades i den slut- giltiga regressionsmodellen. Dessa socialt kapital variabler förklarade 27,5 procent av variationen av självuppskattad hälsa då man kontrollerade för de vanligaste hälsoriskfaktorerna, vilket betyder att sambandet mellan socialt kapital och hälsa var relativt starkt. En svaghet i Hyyppäs och Mäkis studie liksom i de andra studierna i tabell 2 är den bristfälliga informationen om kausaliteten.

Resultaten är inte odelat positiva gällande sambandet mellan socialt kapital och hälsa. I Gerry Veenstras studie i Kanada

Tabell 2.

En sammanfattning av studier som mäter socialt kapital och hälsa.

\begin{tabular}{|l|l|l|l|}
\hline \multicolumn{1}{|c|}{ Studier } & Nivå & \multicolumn{1}{|c|}{ Operationalisering } & \multicolumn{1}{c|}{ Resultat } \\
\hline $\begin{array}{l}\text { Hyyppä \& Mäki, } \\
\text { Finland }\end{array}$ & Individ & $\begin{array}{l}\text { Sociala band och integrering; } \\
\text { vänskap; frivilligt engagemang; } \\
\text { tillit; samhörighet. }\end{array}$ & $\begin{array}{l}\text { Finlandssvenskarna har en högre } \\
\text { nivå av socialt kapital jämfört med } \\
\text { finskspråkiga vilket har en positiv } \\
\text { inverkan på den subjektiva hälsan. }\end{array}$ \\
\hline $\begin{array}{l}\text { Kawachi m.fl., } \\
\text { 1997 }\end{array}$ & Statlig & $\begin{array}{l}\text { Medlemskap i grupper och } \\
\text { föreningar; tillit }\end{array}$ & $\begin{array}{l}\text { En kontextuell effekt mellan dålig } \\
\text { sälvuppskattad hälsa och litet socialt } \\
\text { kapital. }\end{array}$ \\
\hline $\begin{array}{l}\text { Kennelly m.fl., } \\
2003 \\
\text { 19 länder }\end{array}$ & Statlig & Medlemskap i föreningar;tillit & $\begin{array}{l}\text { Litet samband mellan social kapital } \\
\text { och mortalitet. }\end{array}$ \\
\hline $\begin{array}{l}\text { McCulloch, } \\
200 \text { I } \\
\text { Storbritannien }\end{array}$ & Individ & $\begin{array}{l}\text { Frågor om individens grann- } \\
\text { skap. }\end{array}$ & $\begin{array}{l}\text { Ett samband mellan litet socialt } \\
\text { kapital och psykisk sjuklighet. }\end{array}$ \\
\hline $\begin{array}{l}\text { Rose, } \\
2000 \\
\text { Ryssland }\end{array}$ & Individ & $\begin{array}{l}\text { Social integrering: involvering } \\
\text { i olika nätverk, vilka nätverk } \\
\text { individen förlitar sig på i olika } \\
\text { situationer. }\end{array}$ & $\begin{array}{l}\text { Socialt kapital har en större inverkan } \\
\text { på den fysiska och mentala hälsan än } \\
\text { humankapital. }\end{array}$ \\
\hline $\begin{array}{l}\text { Veenstra, } \\
2000 \\
\text { Kanada }\end{array}$ & Individ & $\begin{array}{l}\text { Civilt deltagande såsom frivil- } \\
\text { ligt engagemang, röstningsdel- } \\
\text { tagande mm;tillit }\end{array}$ & $\begin{array}{l}\text { Föga bevis för ett samband mellan } \\
\text { socialt kapital och hälsa. }\end{array}$ \\
\hline
\end{tabular}


(2000) operationaliserades socialt kapital med variabler som tillit och civilt engagemang och han fann föga bevis för ett samband mellan socialt kapital och hälsa då man kontrollerat för utbildning och inkomst. Likaså fann inte Brendan Kennelly m.fl. (2003) ett samband mellan socialt kapital och mortalitet i en jämförande studie omfattande 19 länder.

\section{Några nyckelfrågor beträffande mätningen av socialt kapital}

\section{Kollektivansats}

En av nyckelfrågorna är på vilket sätt man bäst mäter socialt kapital utifrån ett kollektivt perspektiv. Ett sätt är att använda aggregerade individdata som deltagande i grupper och organisationer och tillit och låta svaren representera en övergripande nivå, såsom några av författarna gjort i studierna representerade i tabell 2 (t.ex. Kawachi et al. 1997). Ett annat och mindre empiriskt utarbetat sätt att mäta social kapital på en övergripande nivå är att använda sig av så kallade "helhetsvariabler" (integral variable). Kimberly Lochner m.fl. (1999) ger exempel på hur man kan operationalisera dessa variabler. Som exempel används ifall bensinstationer tar betalt av sina kunder innan de fyller upp tanken eller i vilken utsträckning trottoarerna blir bortsopade på snö efter en snöstorm. Lochner m.fl. motiverar användningen av dylika variabler med att socialt kapital är någonting mer än att enbart använda aggregerade individdata. Socialt kapital är ett karaktärsdrag för den sociala strukturen och inte för den enskilda individen. För att få en uppfattning om den sociala strukturen i samhället måste man således observera och få en uppfattning om samhället i sig. Det är uppenbart att ett dylikt mätinstrument måste vara kulturellt förankrat och det blir problematiskt att utarbeta ett internationellt gångbart mätinstrument.

En av de största utmaningarna idag beträffande forskningen om social kapital och hälsa är att kombinera socialt kapital på en individnivå med socialt kapital på en övergripande nivå och separera dessa förklaringsvärden. Ett metodologiskt sätt som ökar i popularitet är multinivåanalys som används på hierarkiskt organiserat data som exempelvis kommuner och individer inom kommunen. Ett exempel på en svensk studie där man använt multinivåanalys är i Martin Lindström m.fl. (2002) där man i analysen använde individer på den första nivån och grannskap på den andra nivån för att mäta känslan av otrygghet att röra sig i grannskapet efter mörkrets inbrott. Man operationaliserade socialt kapital som en individuell variabel, socialt deltagande, och som en kontextuell variabel, röstningsdeltagande i val. Resultatet visade att socialt kapital på en övergripande nivå delvis kan förklara känslan av otrygghet hos individerna i ett grannskap. Genom att inkludera den kontextuella variabeln (deltagande i val) minskade variansen för de individuella skillnaderna i otrygghet. Fördelen med att använda multinivåanalys är att man undviker att dra felaktiga slutsatser på antingen individnivå eller på en övergripande nivå såsom kommuner eller grannskap. Med hjälp av multinivåanalys kan man således separera individuella och kontextuella förklaringsvärden. 


\section{Kontextens betydelse}

En relevant nyckelfråga är ifall det är möjligt att skapa ett gemensamt mätinstrument för socialt kapital vars giltighet skulle sträcka sig över olika kontexter såsom kulturer, etniska grupper och tidsperioder (Forbes \& Wainwright 2001, Woolcock 2001). I The World Value Survey görs en internationell jämförelse och resultaten visar att speciellt de nordiska länderna har en hög nivå av socialt kapital (t.ex. Knack \& Kneefer 1997). Det har dock höjts kritiska röster mot mätinstrumentets instabilitet i olika kontexter (Woolcock 2001). Speciellt den kulturella miljöns betydelse och dess inverkan på resultatet är ett svårt problem att lösa i dylika internationella studier vilket tydligt framgår i följande kvalitativa studier.

Vicky Cattell och Rachel Herrings (2002) studie ( $\mathrm{N}=40)$ i östra London hade ett flertal syften: att identifiera åldersrelaterade variationer i socialt kapital och vad som påverkar kapitalet, att utforska generationsskillnader samt att utforska sambandet mellan socialt kapital, sociala nätverk och välbefinnande. Åldersgruppen i undersökningen var 15 till 83 år. Speciellt kontextuella frågor visade sig vara viktiga för att förstå processen då socialt kapital skapas. Studien visar betydelsen av den lokala tillgängligheten av service och lokala resurser för att kunna upprätthålla socialt kapital vilket var en relevant aspekt för alla åldersgrupper. Yngre generationer var mera individualistiska än äldre, men uppvisade trots detta inte mindre reciprocitet. De yngre hade dessutom en tolerantare attityd mot andra vilket talar för ett starkare överbyggande socialt kapital (bridging).
Mildred Blaxter och Fiona Polands(2002) empiriska studie var fokuserad på 35 äldre i ett mindre privilegierat bostadsområde i England. Syftet var att utreda ifall olika komponenter av socialt kapital såsom tillit, sociala nätverk, kontroll, reciprocitet, civilt engagemang eller socialt stöd hade någon relevans för respondenternas hälsa. Socialt kapital kategorierna hade använts för en kvantitativ studie (Coulthard et al. 2001) och det andra syftet med denna studie var att testa mätinstrumentets validitet för en äldre målgrupp, dvs. är det möjligt att mäta socialt kapital med standardiserade frågor.

Liksom i Cattell och Herrings studie visade resultaten vikten av att studera en grupp i relation till den sociala, politiska och ekonomiska kontexten. Som en följd anser Blaxter och Poland att kvalitativa studier borde användas som ett komplement till kvantitativa studier. Beviset för detta fann man i intervjuerna av de äldre där det fanns uppenbara svårigheter med att "fånga" socialt kapital på en kollektiv nivå. De äldre fann det lättare att prata om humankapital eller individuellt socialt kapital i termer av personlig styrka, familjen, ekonomiska möjligheter och upplevelser i den egna livshistorien. Som ett resultat av studien förhåller sig Blaxter och Poland kritiska till att använda ett gemensamt universellt instrument för att mäta socialt kapital.

När det gäller etniska minoriteter och socialt kapital och hälsoskillnader har Catherine Campbell och Carl McLean (2002) intervjuat 25 personer i England med afrikanskt och karibiskt ursprung. Personerna bodde i ett multikulturellt område och syftet med studien var att utreda $i$ vilken mån den etniska tillhörigheten 
spelar någon roll för ett civilt engagemang i hälsobefrämjande aktiviteter inom det lokala samhället. Ett av resultaten visar att socialt kapital som en resurs inte är jämlikt fördelat för en grupp inom ett och samma geografiska område. Författarna föreslår att mera uppmärksamhet borde fästas vid hur olika etniska grupper skapar, upprätthåller och har tillgång till socialt kapital.

Vilka slutsatser kan man dra på basen av resultaten från dessa kvalitativa studier? För det första borde forskare vara lyhörda för kontextuella skillnader såsom etniska skillnader och åldersskillnader. För det andra kan man ifrågasätta reliabiliteten och validiteten i internationella kvantitativa studier med tanke på diskussionen som förts inom kvalitativa studier beträffande svårigheten med att standardisera frågor såsom förhållandet till familj, vänner och grannar. Svaren är komplexa och ett stort nätverk behöver inte automatiskt vara en positiv upplevelse för individen. Ett mera omfattande och holistiskt frågeformulär med fokuseringen på att mäta socialt kapital skulle kompensera en del brister som framkommit i internationella studier där man ibland enbart har några frågor till förfogande för att mäta socialt kapital (som t.ex. i World Value Survey).

\section{Diskussion}

Det är inte förvånande att socialt kapital konstaterats påverka hälsan på ett positivt sätt med tanke på den nära kopplingen till nätverksstudier där det redan finns etablerad forskning om hur sociala nätverk och integrering i lokalsamhället påverkar individens välbefinnande. En berättigad fråga man kan ställa sig är vad socialt kapital kan tillföra vår kunskap som vi inte redan har från sociala nätverksstudier. Det finns inte ett enkelt svar på den frågan, som i hög grad är beroende av den teoretiska ansatsen man använder. Socialt kapital på individnivå, enligt Nan Lins definition, visar att bristerna i nätverksstudierna är länken som fattas mellan nätverket och effekterna. Detta har kallats för "theory-gap» av Granovetter. Med detta menas att i de klassiska sociala nätverksstudierna är fokuseringen på nätverksstrukturen, och individens beteende förklaras av hennes position i nätverket, medan i studier om socialt kapital förklaras individens beteende av normerna i nätverket.

Forskare som använder den kollektiva ansatsen påstår att skillnaderna mellan socialt nätverk och socialt kapital främst finns på effektsidan (se Kawachi \& Berkman 2000). Effekten av socialt nätverk och socialt stöd tillfaller den enskilda individen medan socialt kapital tillfaller kollektivet. Därför borde socialt kapital mätas på en kollektivnivå eller ekologisk nivå. En utmaning för forskningen om socialt kapital är således att relatera kapitalet till en övergripande nivå och se hur grupper utnyttjar det sociala kapitalet för gruppens bästa. En annan utmaning är att utifrån ett individoch resursperspektiv relatera socialt kapital till individens nytta, som på en aggregerad nivå även är till nytta för ett större kollektiv. Utmaningarna representerar de två inriktningarna i debatten om socialt kapital, dvs. om man blandar ihop dessa två inriktningar uppstår det spänningar och oklarheter beträffande hur socialt kapital kan bidra exempelvis till epidemiologiska studier. 
Eftersom socialt kapital är ett mångdimensionellt begrepp och existerar på olika nivåer är det viktigt att varje studie definierar begreppet och klargör på vilken nivå man utgår ifrån. James Macinko och Barbara Starfield (2001) har kategoriserat forskningen om socialt kapital och hälsa på minst fyra olika nivåer och menar att en förutsättning för att utveckla och förbättra forskningen är att medvetandegöra på vilken nivå den egna ansatsen finns, vilket inte alltid är uppenbart i dagens forskning. På en makronivå spelar den historiska, sociala, politiska och ekonomiska kontexten en avgörande roll för att förstå socialt kapital. På en mesonivå ligger fokusering på hur lokalsamhället påverkar skapandet och användandet av socialt kapital. Den tredje nivån utgörs av individens beteende såsom socialt deltagande och samarbete med andra medan den fjärde innefattar individens attityder såsom tillit och förtroende.

Det finns flera forskare som talar för en gemensam begreppsdefinition eftersom det finns risk för att begreppet socialt kapital i alltför hög grad överlappar alltför många redan tidigare kända forskningsområden. Men det faktum att det finns flera skilda nivåanalyser av socialt kapital, gör det svårt att hitta en gemensam begreppsdefinition och en gemensam linje för mätning av socialt kapital. Dessutom visar forskningen betydelsen av att beakta kontextuella aspekter vid mätningen av socialt kapital vilket talar mot universella definitioner och operationaliseringar. Åtminstone borde man inte okritiskt kopiera exempelvis Putnams studie, utan att först beakta den egna forskningens kontext. Här får kvalitativa ansatser en central roll för att utveckla studier i socialt kapital.

Ett av syftena med denna artikel har varit att utreda ifall kritiken som riktats mot forskningen om socialt kapital är berättigad. Min slutsats är att den delvis är berättigad och främst på grund av att det är ett relativt nytt forskningsområde med ännu bristfälliga undersökningsmetoder. Det finns forskning som visar på ett starkt samband mellan socialt kapital och hälsa, men vid en närmare granskning av hur begreppet har använts framträder dock flera tydliga svagheter, såsom bristfälliga validitets- och reliabilitetsmätningar, en rätt svag teoretisk förankring samt problem med hur begreppet kan mätas som en kollektiv resurs. 


\section{Referenser}

Avlund Kirsten, Damsgaard Morgens Trab \& Holstein Björn E (1998) "Social relations and mortality. An eleven year follow-up study of 70year-old men and women in Denmark". Social Science and Medicine, 47, 635-643.

Berkman Lisa F, Glass Thomas, Brisette Ian \& Seeman Teresa E. (2000) „From social integration to health: Durkheim in the new millennium». Social Science \& Medicine, 51, 843-857.

Berkman, Lisa F. \& Glass, Thomas (2000) "Social integration, social networks, social support, and health" i Berkman Lisa F \& Kawachi Ichiro (red.) Social Epidemiology. Oxford: University Press.

Berkman, Lisa F. \& Syme, S Leonard (1979) "Social networks, host resistance, and mortality: a nine-year follow-up study of Alameda County residents". American Journal of Epidemiology, 109, 186-204.

Blaxter, Mildred \& Poland, Fiona (2002) "Moving beyond the survey in exploring social capital" i Swann Catherine \& Morgan Antony (red.) Social Capital for Health: Insights form Qualitative Research. London: Health Development Agency.

Bowling, Ann (1991) Measuring Health: a review of quality of life measurement scales. Milton Keynes: Open University Press.

Burt, Ronald S. (1992) Structural Holes. Cambridge: Harvard University Press.

Campbell, Catherine \& McLean, Carl (2002) „Ethnic identities, social capital and health inequalities: factors shaping African-Caribbean participation in local community networks in the UK". Social Science \& Medicine, 55, 643657.

Cattell, Vicky \& Herring, Rachel (2002) "Social capital, generations and health in East London" i Swann Catherine \& Morgan Antony (red.) Social Capital for Health: Insights form Qualitative Research. London: Health Development Agency.

Cohen, Sheldon \& Syme, S. Leonard (1985) "Issues in the study and application of social support» $\mathrm{i}$
Cohen Sheldon \& Syme S. Leonard (red.) Social Support and Health. London: Academic Press.

Coleman, James D. (1988) "Social capital in the creation of human capital«. American Journal of Sociology, 94, Suppl, 95-120.

Coleman, James D. (1990) Foundation of Social Theory. Cambridge and London: The Belknap Press of Harvard University Press.

Coulthard Melissa, Walker Alison \& Morgan Antony (2001) Assessing People's Perception of their own Neighbourhood and Community Involvement (part 1). Health Development Agency: London

Flap, Henk (1999) "Creation and returns of social capital. A new research program". La Revue Tocqueville/The Tocqueville Review, 10, 1-22.

Forbes, Angus \& Wainwright, Steven P. (2001)»On the methodological, theoretical and philosophical context of health inequalities research: a critique». Social Science \& Medicine, 53, 801816.

Fratiglioni Laura, Wang Hui-Xin, Ericsson Kjerstin, Maytan Margaret \& Winblad Bengt (2000) "Influence of social network on occurrence of dementia: a community-based longitudinal study". The Lancet, 355, 1315-1319.

Fukuyama, Francis (1999) The Great Disruption. Human Nature and the Reconstruction of Social Order. London: Profile Books.

Granovetter, Mark (1973) »The strength of weak ties". American Journal of Sociology, 78, 13601380.

Hawe, Penelope \& Shiell, Alan (2000) "Social capital and health promotion: a review". Social Science \& Medicine, 51, 871-885.

Hyyppä, Markku T. \& Mäki, Juhani (2001a) „Individual-level relationships between social capital and self-rated health in bilingual community". Preventive Medicine, 32, 148-155.

Hyyppä, Markku T. \& Mäki, Juhani (2001b) „Why do Swedish-speaking Finns have a longer active life? An area for social capital research". Health Promotion International, 16, 55-64.

Jylhä, Marja \& Aro, Seppo (1989) "Social ties and

Fredrica Nyqvist: Socialt kapital och hälsa - en forskningsöversikt. 
survival among the elderly in Tampere, Finland». International Journal of Epidemiology, 1, 158-164.

Kawachi, Ichiro \& Berkman, Lisa F. (2000) "Social cohesion, social capital, and health" i Berkman Lisa F. \& Kawachi Ichiro (red.) Social Epidemiology. Oxford: University Press.

Kawachi Ichiro, Kennedy Bruce P, Lochner Kimberly \& Prothrow-Stith Deborah (1997) "Social capital, income inequality, and mortality". American Journal of Public Health, 87, 1491-1498.

Kennelly Brendan, O'Shea Eamon \& Garvey Eoghan (2003) "Social capital, life expectancy and mortality: a cross-national examination". Social Science \& Medicine, 56, 2367-2377.

Knack, Stephen \& Kneefer, Philip (1997) „Does social capital have an economic payoff? A cross-country investigation". Quarterly Journal of Economics, 112, 1251-1288.

Lin, Nan (1999) "Building a network theory of social capital». Connections, 22, 28-51.

Lindström Martin, Merlo Juan \& Östergren PerOlof (2002) "Social capital and sense of insecurity in the neighbourhood: a population based multilevel analysis in Malmö, Sweden". Social Science \& Medicine, 56, 1111-1120.

Lochner Kimberly, Kawachi Ichiro \& Kennedy Bruce P (1999) "Social capital: a guide to its measurement». Health \& Place, 5, 259-270.

Luhmann, Niklas (1979) Trust and Power. Chichester: Wiley.

Macinko, James \& Starfield, Barbara (2001) »The utility of social capital in research on health determinants». The Milbank Quarterly, 79, 387-427.

McCulloch, Andrew (2001) "Social environments and health: cross sectional national survey". British Medical Journal, 323, 208-209.

Mitchell, J. Clyde (1969) „The concept and use of social networks" i Mitchell, J.C. (red.) Social Networks in Urban Situations: Analysis of Personal Relationships in Central African Towns. England: Manchester University Press.

Neaigus Alan, Friedman Samuel R, Curtis Richard, Des Jarlais Don C, Furst R. Terry, Jose Benny m.fl. (1994) "The relevance of drug injectors' social and risk networks for understanding and preventing HIV infection". Social Science \& Medicine, 38, 67-78.

Onyx, Jenny \& Bullen, Paul (1997) Measuring Social Capital in Five Communities in NSW: A Practitioners Guide. Centre for Community Organisations and Management Working Paper Series No. 4l, University of Technology, Sydney.

Portes, Alejandro (1998) "Social capital: its origins and applications in modern sociology". Annual Reviews Sociology, 24, 1-24.

Putnam, Robert D. (1996) Den fungerande demokratin. Medborgarnas rötter i Italien. Stockholm: Norstedts Tryckeri AB.

Putnam, Robert D. (2000) Bowling alone: the collapse and revival of American community. New York: Simon \& Schuster.

Putnam, Robert D. (2001) "Social capital: measurement and consequences". ISUMA, 2, 41-51.

Rose, Richard (2000) "How much social capital add to individual health? A survey study of Russians". Social Science \& Medicine, 51, 1421-1453.

Sampson, Robert J. \& Raudenbush, Stephen W. (1997) „Neighbourhoods and violent crime: a multilevel study of collective efficacy». Science, 5328, 918-925.

Seeman, Teresa E (1996) "Social ties and health: the benefits of social integration". Annals of Epidemiology, 6, 442-451.

Seligman, Adam (1997) The Problem of Trust. Princeton, NJ: Princeton University Press.

Stone, Wendy (2001) Measuring social capital. Towards a theoretically informed measurement framework for researching social capital in family and community life. Research paper no. 24, Australian Institute of Family Studies.

Thoits, Peggy A. (1985) "Social support and psychological well-being: theoretical possibilities" i Sarason Irwin G. \& Sarason Barbara R. (red.) Social Support: Theory, Research and Applications. Dordrecht/Boston/Lancaster: Marinus Nijhoff Publishers.

Veenstra, Gerry (2000) "Social capital, SES and health: an individual-level analysis». Social Science \& Medicine, 50, 619-629. 
Woolcock, Michael (1998) "Social capital and economic development: toward a theoretical synthesis and policy framework". Theory and Society, 27, 151-208.

Woolcock, Michael (2001) "The place of social capital in understanding social and economic outcomes« i Helliwell, John F (red.) The Contri- bution of Human and Social Capital to Sustained Economic Growth and Well-being: International Symposium Report. Human Resources Development Canada and OECD.

World Value Survey (1996-1997) http://wvs.isr umich.edu

\section{Summary}

\section{Social capital and health A research overview}

There is a major scientific interest in the concept of social capital. In the literature we find that social capital has a positive effect on democracy, well-being, physical and mental health, quality of life, poverty, crime reduction and economic growth. Because of its popularity there is a danger that it is becoming an overloaded concept with confusion about meaning, measurement and outcome. The concept has been accused of not bringing any new significant knowledge to health research. This article evaluates whether the critique is justified. As a starting point the focus is on major theorists within this field and their assumptions about the meaning and outcome of the concept. As a result a distinction is made between individual-level social capital and group-level social capital.

The article highlights the key components, i.e. social network, reciprocity and trust. Finally, studies exploring the relationship between social capital and health are summarized and difficulties regarding measurement are discussed. While identifying many similarities with related concepts, there is an overwhelming risk to the concept's scientific relevance for future research. To sum up, social capital is a promising concept but more theoretically derived research is necessary for the survival of the concept in health research. 